\title{
Patient satisfaction with care in an urban tertiary referral academic glaucoma clinic in the US
}

This article was published in the following Dove Press journal:

Patient Preference and Adherence

\section{Kristen M Peterson \\ Carrie E Huisingh \\ Christopher Girkin \\ Cynthia Owsley \\ Lindsay A Rhodes}

Department of Ophthalmology, School of Medicine, University of Alabama at Birmingham, Birmingham, AL, USA
Correspondence: Lindsay A Rhodes Department of Ophthalmology, University of Alabama at Birmingham, EFH 60I, I 720 2nd Avenue South, Birmingham, AL 35294, USA

Tel +l 2053258635

Fax + I 2053258692

Email lindsayrhodes@uabmc.edu
Background: The purpose of this study was to determine the factors associated with glaucoma patients' satisfaction with their medical care by fellowship-trained glaucoma specialists in an urban tertiary referral clinic in the US.

Methods: A total of 110 established patients aged $\geq 60$ years with a diagnosis of either primary open angle glaucoma, glaucoma suspect, or ocular hypertension monitored by an ophthalmologist with fellowship training in glaucoma were enrolled at an academic, urban, tertiary referral eye clinic. Enrolled patients were administered a general demographics questionnaire along with a Patient Satisfaction Questionnaire-18 (PSQ-18), a Likert scale validated tool. The seven dimensions of patient satisfaction from the PSQ-18 were summarized for the sample overall and by the patients' age, race, employment status, education level, distance travelled from home address to clinic, and glaucoma therapy type. Two-sample $t$-tests were used to compare group means. Spearman correlation coefficients were used to correlate satisfaction scores with peripheral vision and visual acuity function.

Results: Overall, the general satisfaction scores were high (mean 4.62). Patients $\geq 70$ years of age had lower general satisfaction with their care (mean 4.5 vs $4.8, p=0.03$ ), the interpersonal manner of their appointment (mean 4.7 vs $4.9, p=0.009$ ), and with their time spent with their doctor (mean 4.4 vs $4.7, p=0.03$ ) than patients aged 60-69 years. Non-European descent patients (47\% African descent and 1\% other of sample) were more satisfied with the time they spent with the doctor (mean 4.7 vs $4.4, p=0.04$ ) and with the communication during the appointment (mean 4.8 vs $4.6, p=0.04$ ) than European descent patients ( $52 \%$ of sample). Patients with a higher level of education ( $>$ high school degree) were less satisfied with the accessibility and convenience of the appointment (mean 4.3 vs $\leq$ high school, $4.6, p=0.02$ ). There were no statistically significant differences in patient satisfaction based upon employment status, distance travelled to clinic, prior glaucoma therapy, or visual function.

Conclusion: Overall, across all dimensions of the PSQ-18, patients were highly satisfied with the care they received at the urban tertiary care glaucoma clinic.

Keywords: patient satisfaction, glaucoma, tertiary care, access to care, adherence, barriers to care

\section{Introduction}

Glaucoma is one of the most common chronic eye diseases of aging and is the second most common cause of blindness worldwide. ${ }^{1}$ In 2010, there were 60.5 million people worldwide with glaucoma. The prevalence of primary open angle glaucoma (POAG) increases with age; due to the rapid anticipated growth of the aging population, the number of people diagnosed with glaucoma is expected to increase to 111.8 million people worldwide by $2040 .^{2}$ The at-risk population for glaucoma in the US is large, with older age as the primary risk factor as well as being of African descent or Hispanic $\geq 40$ years old, being of European descent $\geq 50$ years old, older persons 
with diabetes, and those with a family history of glaucoma. Glaucoma is at least 4-5 times higher in those of African descent, progresses more rapidly and appears about 10 years earlier as compared to those of European descent. ${ }^{3-10}$ There are both primary and secondary forms of glaucoma but all are characterized by damage to the optic nerve, thinning of the retinal nerve fiber layer, and irreversible peripheral vision loss that in advanced disease extends into the central vision.

Patients followed for glaucoma in the US are routinely seen several times a year by an ophthalmologist or optometrist to monitor for progressive optic nerve damage. During these visits, the patient may receive one or more of the following: measurement of the intraocular pressure; optic nerve imaging; and/or functional peripheral visual field testing. Treatment for glaucoma consists of daily prescription eye drops to reduce intraocular pressure medically. Patients with advanced or progressive disease are often referred to an ophthalmologist with fellowship training in glaucoma for expert care. More invasive treatments to decrease or halt the progression of glaucoma are often necessary and may include laser or incisional surgery to reduce intraocular pressure.

Older adults with glaucoma, especially in advanced stages, experience reductions in health-related quality of life with an increased risk for depression, social disengagement, employment challenges, problems accessing health care, and ultimately, mortality. ${ }^{11-21}$ Interventions to improve early detection of glaucoma and increase follow-up rates, including how to make care more accessible and satisfactory for glaucoma patients, will likely improve the health and well-being of people with this condition. Among ophthalmologists, it is well known that non-compliance with topical drop therapy to control intraocular pressure results in worse visual outcomes. ${ }^{22-24}$ Numerous factors have been found in the literature to be associated with poor compliance with drop regimens, two of which directly relate to our study population - age: $\geq 80$ years and race: African descent. ${ }^{22,23}$ It is imperative that we identify factors that improve patient compliance both with treatment regimens and attending scheduled appointments in order to prevent glaucoma progression. It is our hope that if patients are more satisfied with their glaucoma clinic visits then they may be more likely to comply with medical treatments and follow-up appointments.

Little is currently known regarding patients' satisfaction with the care they receive in tertiary glaucoma clinics in the US. What is known about patient satisfaction with care largely comes from studies in the UK where the health care system infrastructure varies significantly from that in the US.
Levy et $\mathrm{al}^{25}$ administered a patient satisfaction survey to glaucoma patients treated in a community optometry clinic in the UK and found that $90.4 \%$ of patients surveyed $(n=80)$ were either very satisfied or satisfied with their care. ${ }^{25}$ Additionally, when asked how their experience in the community optometry clinic compared to their experience with the Hospital Eye Service (where patients are seen by ophthalmologists), $43.8 \%$ reported the care was "better" in the community clinic with another $42.5 \%$ reporting it was the "same". ${ }^{25}$ In a similar UK study of a community optometry glaucoma clinic, patients cited shorter wait times to see the optometrist as a key aspect that improved their overall experience and level of satisfaction. ${ }^{26}$ In comparison, in the southern US where ophthalmology practices are rarely located in rural counties, accessibility (ie, transportation, nearness of clinic to where one resides) was the most commonly cited barrier to eye care by those of African descent in the region. ${ }^{16}$

The aim of this study was to determine the factors associated with glaucoma patients' satisfaction with their medical care for glaucoma in an urban tertiary referral clinic, staffed by ophthalmologists with fellowship training in glaucoma, among a patient population comprising predominantly African descent patients.

\section{Methods}

This study was approved by the Institutional Review Board at the University of Alabama at Birmingham (UAB) and followed the tenets of the Declaration of Helsinki. This was a prospective cross-sectional study of glaucoma patients who were seen by either of two glaucoma fellowship-trained attending ophthalmologists in the Glaucoma Clinic of the Callahan Eye Hospital Clinic at UAB. This glaucoma clinic sees patients from the regional community seeking eye care as well as referrals from other eye care providers from the state of Alabama. Patients are insured with Medicare, Medicaid, or private insurance. In 2017, the UAB Glaucoma Clinic saw over 9,700 patients with POAG, ocular hypertension, or glaucoma suspect, of whom $41 \%$ were of African descent and $52 \%$ of European descent.

Potential study participants were identified from the scheduled list of patients for the two glaucoma specialists based on their age and status as an established patient with a glaucoma-associated diagnosis previously made by the glaucoma specialist. Eligibility criteria for enrollment were English speaking, had attended $>1$ visit at the glaucoma clinic previously, and $\geq 60$ years of age with a diagnosis of either POAG, ocular hypertension, and/or glaucoma suspect. Enrollment took place from 5/5/2015-7/18/2015. 
Eligible patients were asked to participate by a research coordinator after checking in for their scheduled glaucoma appointment. Participants provided written informed consent after the nature and purpose of the study were described. Two questionnaires were administered in a private room prior to the patient's eye exam by the research coordinator: a general patient demographic questionnaire (age, sex, race/ethnicity, education completed, and employment status) and a Patient Satisfaction Questionnaire Short Form (PSQ-18). ${ }^{27}$ The PSQ-18 has been validated for use in a variety of settings and has established internal consistency and reliability. ${ }^{27,28}$ Responses are on a Likert scale ranging from 1 (strongly agree) to 5 (strongly disagree) and assess seven dimensions of patient satisfaction directed toward doctors including general satisfaction, technical quality, interpersonal manner, communication, financial aspects, time spent with doctor, and accessibility and convenience. In order to make the survey more specific to glaucoma care, we replaced the word "medical" with "glaucoma" in the individual survey questions. Negatively and positively worded items in each subscale were scored such that high scores reflect more satisfaction; items within the same subscale were averaged together to create the seven dimension scores per the instructions. ${ }^{27}$ Glaucoma severity was determined based on the most recently completed visual field index (VFI) score obtained from automated visual field testing with Swedish interactive thresholding algorithm 24-2. VFI is a measure in the StatPac software of the Humphrey Field Analyzer (Carl Zeiss Meditec, Dublin, CA, USA). It is scored as a percentage ranging from 100 representing normal visual field to 0 representing absolute perimetric loss. ${ }^{29}$ Visual acuity was defined as the distance visual acuity measured with refraction at the visit and expressed as logarithm of the minimum angle of resolution (logMAR). ${ }^{30}$ The ocular history, VFI, and visual acuity were obtained by chart review performed by the research coordinator.

Demographic and clinical characteristics were summarized for the sample overall. Two-sample $t$-tests were used to compare the mean PSQ-18 dimension scores by age group (60-69 vs $\geq 70$ ), race (European descent vs non-European descent), employment status (yes vs no), educational attainment ( $\leq$ high school [HS] degree vs $>$ HS degree), distance travelled to clinic from home address (quartiles of miles compared) as well as by history of any glaucoma-related medication use (yes vs no), glaucoma laser treatment (yes vs no), or glaucoma surgery (yes vs no). Spearman correlation coefficients were used to assess the relationship between mean
PSQ-18 subscale scores with glaucoma severity based on visual acuity and VFI for the better and worse eye.

\section{Results}

A total of 110 patients were enrolled during the study period. Mean age of participants was 71.2 years ( $\mathrm{SD} \pm 6.7$, Table 1). About half (47\%) self-reported as being of African descent, $52 \%$ were of European descent, and 1\% listed other. Employment ( $20 \%$ currently employed) and level of education ( $\leq$ HS 33\%) were used as markers of socioeconomic status. The mean distance in miles from patients' home address to the clinic address was 40.3 ( $\mathrm{SD} \pm 48.4)$. Mean VFI for the better eye in enrolled patients was 76.3 ( $\mathrm{SD} \pm 34.4$ ) as compared to 55.1 ( $\mathrm{SD} \pm 40.2)$ in the worse-seeing eye. The mean VA $\log M A R$ in the better-seeing eye was $0.26(\mathrm{SD} \pm 0.4)$ and $0.48(\mathrm{SD} \pm 0.6)$ in the worse-seeing eye. The vast majority (92\%) of patients had been prescribed a pressure-lowering ophthalmic drop over the past year with $12 \%$ having undergone a pressure-lowering laser procedure and $31 \%$ of patients having undergone glaucoma surgery within the year preceding the study.

Analysis of study participants' satisfaction with their tertiary clinic glaucoma care based on their responses to the PSQ-18 survey revealed that overall the group of patients had high satisfaction levels on the PSQ-18 dimensions, ranging from a mean of $4.42(\mathrm{SD} \pm 0.670)$ to $4.79(\mathrm{SD} \pm 0.513)$ (Table 2). Patients between the age of 60 and 69 years were

Table I Demographic, educational, and clinical characteristics of the sample $(\mathrm{N}=\mathrm{I} / 0)$

\begin{tabular}{|c|c|}
\hline Characteristics & $\begin{array}{l}\text { Mean }( \pm S D) \\
\text { or } \mathbf{n}(\%)\end{array}$ \\
\hline Age, years & $71.2( \pm 6.7)$ \\
\hline Sex, female & $63(57.3)$ \\
\hline \multicolumn{2}{|l|}{ Race } \\
\hline African descent & $52(47.3)$ \\
\hline European descent & $57(51.8)$ \\
\hline Other & $\mathrm{I}(0.9)$ \\
\hline Currently employed, yes & $22(20.0)$ \\
\hline Education level, $\leq$ high school & $36(32.7)$ \\
\hline Distance between clinic and patient home address, miles & $40.3( \pm 48.4)$ \\
\hline \multicolumn{2}{|l|}{ Glaucoma severity } \\
\hline Visual acuity, better eye VA logMAR ${ }^{a}$ & $0.26( \pm 0.4)$ \\
\hline Visual acuity, worse eye VA logMAR ${ }^{a}$ & $0.48( \pm 0.6)$ \\
\hline Visual field, better eye VFI ${ }^{b}$ & $76.3( \pm 34.4)$ \\
\hline Visual field, worse eye VFI ${ }^{b}$ & $55.1( \pm 40.2)$ \\
\hline \multicolumn{2}{|l|}{ Glaucoma treatment } \\
\hline Glaucoma medications prescribed in past year, yes ${ }^{c}$ & $97(91.5)$ \\
\hline Glaucoma laser in past year, yes ${ }^{c}$ & $13(12.3)$ \\
\hline Glaucoma surgery in past year, yes ${ }^{c}$ & $33(31.1)$ \\
\hline
\end{tabular}

Note: ${ }^{a} \mathrm{~N}=100 ;{ }^{b} \mathrm{~N}=93 ;{ }^{\mathrm{c}} \mathrm{N}=106$.

Abbreviations: SD, standard deviation; VA, visual acuity; logMAR, logarithm of the minimum angle of resolution; VFI, visual field index. 


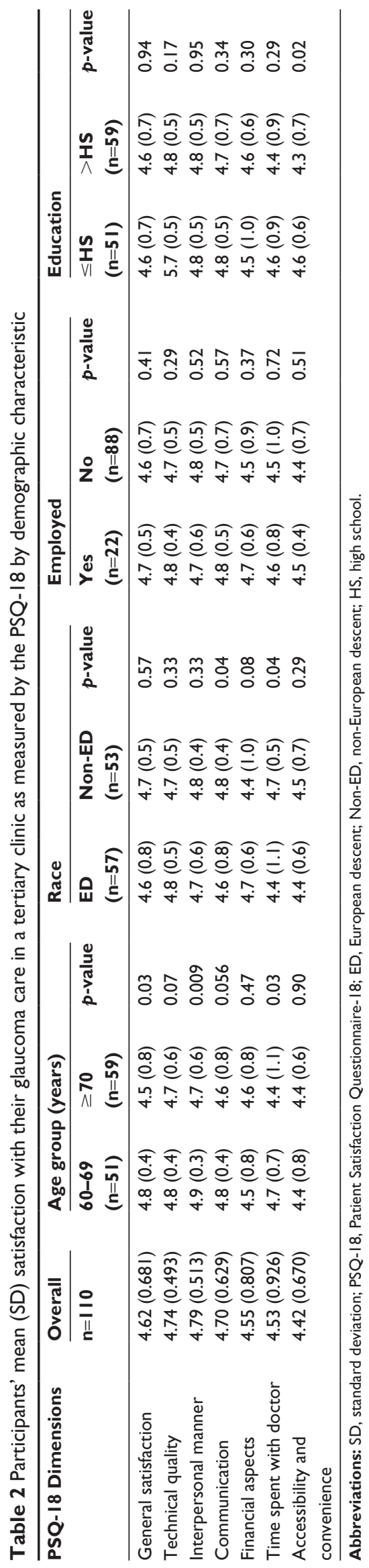

generally more satisfied with their care, the interpersonal manner of their appointment, and with their time spent with their doctor than patients over the age of 70 years (mean Likert scores 4.8, 4.9, 4.7; $p=0.03,0.009,0.03$, respectively) (Table 2). When analyzed based on race, non-European descent participants were more satisfied with the communication that they received in the appointment $(p=0.04)$ as well as with the time they spent with the doctor $(p=0.04)$ as compared to their fellow white participants. There were no statistically significant differences in patient satisfaction when analyzed based on employment status or distance travelled to the clinic. However, patients with greater than a HS level of education were less satisfied with the accessibility and convenience of the appointment $(p=0.02)$ (Table 2). There were no statistically significant differences in PSQ-18 dimension scores and the distance patients travelled from home to the clinic (data not shown).

There were no statistically significant differences in participants' satisfaction for any of the PSQ-18 dimensions based upon the previous glaucoma therapy the patients had received (glaucoma medications, prior glaucoma laser procedures, or prior glaucoma surgery) (Table 3). Similarly, there was no statistically significant difference in the correlation coefficient between patients' satisfaction with their glaucoma care and their level of visual function as determined by their visual acuity and visual field (Table 4).

\section{Discussion}

In this cross-sectional study of older glaucoma patients' satisfaction at an urban tertiary referral center in the US, overall the study participants, based on the Likert scale means, reported that they were highly satisfied with their care across all the PSQ-18 dimensions, suggesting that the conventional model of care is satisfactory in many ways to patients in this setting. Of the seven PSQ-18 dimensions, only a few subgroups showed statistically significant differences in patient satisfaction based on the patient factors we examined. The accessibility and convenience of the clinic appointment had a significantly lower satisfaction level among patients who had received education beyond a HS degree. European descent patients were significantly less satisfied with the communication they received during the appointment and the time they spent with their doctor. It should be noted that both of the glaucoma physicians involved in this study are of European descent. While the literature supports the notion that minority patients are more likely to have a minority primary care physician, a recently published observational retrospective review on patient satisfaction did not show a 
Table 3 Participants' mean (SD) satisfaction with their glaucoma care in a tertiary clinic as measured by the PSQ- 8 by glaucoma treatment

\begin{tabular}{|c|c|c|c|c|c|c|c|c|c|}
\hline \multirow[t]{2}{*}{ PSQ-I 8 Dimensions } & \multicolumn{3}{|c|}{ Glaucoma medications } & \multicolumn{3}{|c|}{ Glaucoma laser } & \multicolumn{3}{|c|}{ Glaucoma surgery } \\
\hline & $\begin{array}{l}\text { Yes } \\
(n=97)\end{array}$ & $\begin{array}{l}\text { No } \\
(n=9)\end{array}$ & $p$-value & $\begin{array}{l}\text { Yes } \\
(n=13)\end{array}$ & $\begin{array}{l}\text { No } \\
(n=93)\end{array}$ & $p$-value & $\begin{array}{l}\text { Yes } \\
(n=33)\end{array}$ & $\begin{array}{l}\text { No } \\
(n=73)\end{array}$ & $p$-value \\
\hline General satisfaction & $4.6(0.7)$ & $4.7(0.4)$ & 0.65 & $4.8(0.4)$ & $4.6(0.7)$ & 0.42 & $4.6(0.8)$ & $4.6(0.6)$ & 0.75 \\
\hline Technical quality & $4.7(0.5)$ & $4.8(0.4)$ & 0.85 & $4.8(0.4)$ & $4.7(0.5)$ & 0.99 & $4.8(0.4)$ & $4.7(0.5)$ & 0.57 \\
\hline Interpersonal manner & $4.8(0.5)$ & $4.7(0.6)$ & 0.67 & $4.8(0.6)$ & $4.8(0.5)$ & 0.86 & $4.7(0.6)$ & $4.8(0.5)$ & 0.38 \\
\hline Communication & $4.7(0.6)$ & $4.7(0.6)$ & 0.88 & $4.7(0.6)$ & $4.7(0.6)$ & 0.97 & $4.7(0.6)$ & $4.7(0.7)$ & 0.86 \\
\hline Financial aspects & $4.5(0.8)$ & $4.7(0.7)$ & 0.47 & $4.3(1.0)$ & $4.6(0.8)$ & 0.38 & $4.5(1.0)$ & $4.6(0.7)$ & 0.64 \\
\hline Time spent with doctor & $4.5(1.0)$ & $4.6(0.7)$ & 0.89 & $4.7(1.0)$ & $4.5(0.9)$ & 0.57 & $4.4(1.1)$ & $4.6(0.9)$ & 0.32 \\
\hline Accessibility and convenience & $4.4(0.7)$ & $4.4(0.6)$ & 0.96 & $4.4(0.7)$ & $4.4(0.7)$ & 0.91 & $4.5(0.5)$ & $4.4(0.7)$ & 0.58 \\
\hline
\end{tabular}

Note: No associations were statistically significant.

Abbreviations: SD, standard deviation; PSQ-18, Patient Satisfaction Questionnaire-18.

statistically significant difference in patient ratings of their physician based on their physician's race or ethnicity. ${ }^{31,32}$ The subgroup of patients that was overall significantly least satisfied with the care they received was in patients over 70 years of age who reported a lower general level of satisfaction, less satisfaction with the amount of time spent with their doctor, and less satisfaction with the interpersonal interactions during the appointment.

This study is innovative and relevant given that 1) few prior studies have addressed patient satisfaction with glaucoma care in an urban tertiary referral clinic in the US and 2) this study evaluates if such a model of care is embraced by older patients with glaucoma or if there are barriers to care limiting patient satisfaction. Such barriers to care identified in the study include the accessibility and convenience of the clinic, time spent with the doctor, communication with the doctor, and the interpersonal manner of the doctor. Glen et al similarly found that the quality of patient-doctor communication and ease of travel to the clinic location were repeatedly identified as barriers to care by glaucoma patients in focus groups. ${ }^{33}$ If patients are less likely to follow through with routine visits due to a perceived barrier to care, that may result in less time spent with their physician and therefore decreased time receiving counseling and education on the disease process and treatment regimen. Reported reasons for poor adherence resulting in lower compliance rate among a group of glaucoma patients in the UK include lack of motivation, poor education, forgetfulness, and drop application. ${ }^{34}$ Many of these factors can be mediated with physician-patient communication and patient education. Studies have shown that patient-reported opinion of their communication with their physician significantly contributes to their compliance with glaucoma drops and their ability to cope with their disease. ${ }^{35-37}$ Additionally, it has been shown that in patients with newly diagnosed glaucoma, anxiety levels decrease when they receive additional counseling regarding their disease process. ${ }^{35,36,38}$ Therefore, understanding patients' satisfaction with their glaucoma care in an urban tertiary care clinic, a widely utilized model of care across the country, has implications

Table 4 Correlation coefficient between participants' satisfaction with their glaucoma care in a tertiary clinic as measured by the PSQ- 18 and visual function

\begin{tabular}{lllll}
\hline PSQ-18 Dimensions & $\begin{array}{l}\text { Visual field } \\
\text { (better eye) }^{\mathbf{a}}\end{array}$ & $\begin{array}{l}\text { Visual field } \\
\text { (worse eye) }^{\mathbf{a}}\end{array}$ & $\begin{array}{l}\text { VA } \\
\text { (better eye) }^{\mathbf{b}}\end{array}$ & $\begin{array}{l}\text { VA } \\
\text { (worse eye) }^{\mathbf{b}}\end{array}$ \\
\hline General satisfaction & -0.11 & -0.08 & -0.05 & -0.02 \\
Technical quality & 0.04 & 0.13 & 0.03 & 0.12 \\
Interpersonal manner & -0.06 & 0.04 & -0.03 & 0.07 \\
Communication & -0.09 & -0.05 & 0.06 & 0.12 \\
Financial aspects & 0.15 & 0.14 & -0.09 & -0.08 \\
Time spent with doctor & -0.07 & -0.07 & -0.05 & -0.05 \\
Accessibility and convenience & -0.10 & -0.20 & 0.09 & 0.09 \\
\hline
\end{tabular}

Notes: axpressed as the Visual Field Index. $\mathrm{N}=93$. ${ }^{\mathrm{b}}$ Expressed as logarithm of the minimum angle of resolution. $\mathrm{N}=100$. No associations were statistically significant. Abbreviations: PSQ-18, Patient Satisfaction Questionnaire-18; VA, visual acuity. 
that influence patient care and can therefore mitigate further vision loss.

All patients enrolled in this study were treated at a tertiary referral center by fellowship-trained glaucoma physicians. As expected, these patients in general had fairly advanced glaucoma as evidenced by their visual acuity and VFI and further supported by the fact that $97 \%$ of patients had received glaucoma medications, $13 \%$ had required glaucoma laser therapy, and 33\% had undergone glaucoma surgery within the past year. Therefore, understanding patient satisfaction in this subgroup of glaucoma patients who are more likely to require closer follow-up and more intensive treatment regimens is imperative to maximize the patients' chances of remaining compliant with their scheduled appointments and glaucoma therapies and hopefully thereby minimizing further optic nerve damage and loss of vision. Future directions for research into improving the care experience of glaucoma patients include identifying methods to monitor visual changes and glaucoma progression through remote web-based technology such as telemedicine and online tools..$^{39,40}$

One limitation of our study is that the survey questionnaire was administered prior to the patient being seen by a physician. Although the physicians did not know who elected to participate in the study and did not have access to the survey results prior to the patient visit, it is possible that the patients may have been concerned that if they did not answer the questionnaire positively that it may in some way affect their care or relationship with their doctor. However, the patients in this study all had more than one prior visit with the physician and had likely already formed an opinion on the physician from previous visits. Future studies may consider administering the questionnaire at the completion of the appointment or at a later date. Another limitation is that although the satisfaction survey administered has been used in a variety of health care settings, it is a generic patient satisfaction survey and thus may not have captured barriers to care for this specific older glaucoma patient population. Future studies could consider using a survey created for such a population or incorporating open-ended questions for patients to express specific concerns. Additionally, the data presented here represent patients in a single clinic, cared for by one of two glaucoma specialists, and thus the generalizability to other clinic settings is unknown. Lastly $99 \%$ of the patients in the study self-identified as being of either European or African descent and therefore the perception of other racial/ethnic groups cannot be extrapolated from this data.

\section{Conclusion}

Overall, the glaucoma patients' satisfaction with their glaucoma care as assessed by the PSQ-18 measured dimensions was high. Our study results confirm that this current conventional and largely universal model of care is well received by most glaucoma patients. This is encouraging for the management of the current population of patients with glaucoma since this is the typical model of care in the US and has positive implications for the expansive population of glaucoma patients expected in the upcoming 20 years. However, limited accessibility and convenience of tertiary care clinics did reduce satisfaction among more educated patients and may become more of an issue as the demand for glaucoma care increases.

\section{Acknowledgments}

This research was supported by a grant from the National Institute of Aging (NIH/NIA P30 AG022838) and a National Eye Institute grant (NIH/NEI 1K23EY025724-01A1), with supplemental support from the EyeSight Foundation of Alabama, Birmingham, AL, USA, and Research to Prevent Blindness, New York, NY.

\section{Disclosure}

The authors report no conflicts of interest in this work.

\section{References}

1. Chow JTY, Hutnik CML, Solo K, Malvankar-Mehta MS. When is evidence enough evidence? A systematic review and meta-analysis of the trabectome as a solo procedure in patients with primary open-angle glaucoma. J Ophthalmol. 2017;2017:2965725.

2. Tham YC, Li X, Wong TY, Quigley HA, Aung T, Cheng CY. Global prevalence of glaucoma and projections of glaucoma burden through 2040: a systematic review and meta-analysis. Ophthalmology. 2014; 121(11):2081-2090.

3. Coulehan JL, Helzlsouer KJ, Rogers KD, Brown SI. Racial differences in intraocular tension and glaucoma surgery. Am J Epidemiol. 1980; 111(6):759-768.

4. David R, Livingston D, Luntz MH. Ocular hypertension: a comparative follow-up of black and white patients. Br J Ophthalmol. 1978;62(10): 676-678.

5. Grant WM, Burke JF Jr. Why do some people go blind from glaucoma? Ophthalmology. 1982;89(9):991-998.

6. JavittJC, McBean AM, Nicholson GA, Babish JD, Warren JL, Krakauer H. Undertreatment of glaucoma among black Americans. N Engl J Med. 1991;325(20):1418-1422.

7. Martin MJ, Sommer A, Gold EB, Diamond EL. Race and primary open-angle glaucoma. Am J Ophthalmol. 1985;99(4):383-387.

8. Sommer A, Tielsch JM, Katz J, et al. Racial differences in the causespecific prevalence of blindness in east Baltimore. N Engl J Med. 1991; 325(20):1412-1417.

9. Tielsch JM, Sommer A, Katz J, Royall RM, Quigley HA, Javitt J. Racial variations in the prevalence of primary open-angle glaucoma. The Baltimore Eye Survey. JAMA. 1991;266(3):369-374.

10. Wilensky JT, Gandhi N, Pan T. Racial influences in open-angle glaucoma. Ann Ophthalmol. 1978;10(10):1398-1402. 
11. Cheng HC, Guo CY, Chen MJ, Ko YC, Huang N, Liu CJ. Patientreported vision-related quality of life differences between superior and inferior hemifield visual field defects in primary open-angle glaucoma. JAMA Ophthalmol. 2015;133(3):269-275.

12. Haymes SA, Leblanc RP, Nicolela MT, Chiasson LA, Chauhan BC. Risk of falls and motor vehicle collisions in glaucoma. Invest Ophthalmol Vis Sci. 2007;48(3):1149-1155.

13. Matthews K, Nazroo J, Whillans J. The consequences of self-reported vision change in later-life: evidence from the English Longitudinal Study of Ageing. Public Health. 2017;142:7-14.

14. McGwin G Jr, Xie A, Mays A, et al. Visual field defects and the risk of motor vehicle collisions among patients with glaucoma. Invest Ophthalmol Vis Sci. 2005;46(12):4437-4441.

15. Orta AÖ, Özturker ZK, Erkul SÖ, Bayraktar Ş, Yilmaz OF. The correlation between glaucomatous visual field loss and vision-related quality of life. J Glaucoma. 2015;24(5):e121-e127.

16. Owsley C, McGwin G, Scilley K, Girkin CA, Phillips JM, Searcey K. Perceived barriers to care and attitudes about vision and eye care: focus groups with older African Americans and eye care providers. Invest Ophthalmol Vis Sci. 2006;47(7):2797-2802.

17. Parrish RK 2nd, Gedde SJ, Scott IU, et al. Visual function and quality of life among patients with glaucoma. Arch Ophthalmol. 1997;115(11): 1447-1455.

18. Rees G, Tee HW, Marella M, Fenwick E, Dirani M, Lamoureux EL. Vision-specific distress and depressive symptoms in people with vision impairment. Invest Ophthalmol Vis Sci. 2010;51(6):2891-2896.

19. Ringsdorf L, McGwin G Jr, Owsley C. Visual field defects and visionspecific health-related quality of life in African Americans and whites with glaucoma. J Glaucoma. 2006;15(5):414-418.

20. Sherwood MB, Garcia-Siekavizza A, Meltzer MI, Hebert A, Burns AF, McGorray S. Glaucoma's impact on quality of life and its relation to clinical indicators. A pilot study. Ophthalmology. 1998;105(3):561-566.

21. Jones L, Bryan SR, Crabb DP. Gradually then suddenly? Decline in vision-related quality of life as glaucoma worsens. J Ophthalmol. 2017; 2017:1621640.

22. Chang DS, Friedman DS, Frazier T, Plyler R, Boland MV. Development and validation of a predictive model for nonadherence with once-daily glaucoma medications. Ophthalmology. 2013;120(7):1396-1402.

23. Friedman DS, Quigley HA, Gelb L, et al. Using pharmacy claims data to study adherence to glaucoma medications: methodology and findings of the Glaucoma Adherence and Persistency Study (GAPS). Invest Ophthalmol Vis Sci. 2007;48(11):5052-5057.

24. Okeke CO, Quigley HA, Jampel HD, et al. Adherence with topical glaucoma medication monitored electronically the Travatan Dosing Aid study. Ophthalmology. 2009;116(2):191-199.

25. Levy S, Booth A. Patient satisfaction with Peninsula Optometry Community Glaucoma Scheme. Eye (Lond). 2015;29(10):1395.
26. Gray SF, Spencer IC, Spry PG, et al. The Bristol Shared Care Glaucoma Study - validity of measurements and patient satisfaction. J Public Health Med. 1997;19(4):431-436.

27. Marshall GN, Hays RD. The Patient Satisfaction Questionnaire ShortForm (PSQ-18). Santa Monica, CA: RAND; 1994.

28. Ware JE Jr, Snyder MK, Wright WR, Davies AR. Defining and measuring patient satisfaction with medical care. Eval Program Plann. 1983; 6(3-4):247-263.

29. Lee JM, Cirineo N, Ramanathan M, et al. Performance of the visual field index in glaucoma patients with moderately advanced visual field loss. Am J Ophthalmol. 2014;157(1):39-43.

30. Beck RW, Moke PS, Turpin AH, et al. A computerized method of visual acuity testing: adaptation of the early treatment of diabetic retinopathy study testing protocol. Am J Ophthalmol. 2003;135(2):194-205.

31. Chen JG, Zou B, Shuster J. Relationship between patient satisfaction and physician characteristics. J Patient Exp. 2017;4(4):177-184.

32. Gray B, Stoddard JJ. Patient-physician pairing: does racial and ethnic congruity influence selection of a regular physician? J Community Health. 1997;22(4):247-259.

33. Glen FC, Baker H, Crabb DP. A qualitative investigation into patients' views on visual field testing for glaucoma monitoring. BMJOpen. 2014; 4(1):e003996

34. Lacey J, Cate H, Broadway DC. Barriers to adherence with glaucoma medications: a qualitative research study. Eye (Lond). 2009;23(4) 924-932.

35. Killeen OJ, MacKenzie C, Heisler M, Resnicow K, Lee PP, NewmanCasey PA. User-centered design of the eyeGuide: a tailored glaucoma behavior change program. J Glaucoma. 2016;25(10):815-821.

36. Taylor SA, Galbraith SM, Mills RP. Causes of non-compliance with drug regimens in glaucoma patients: a qualitative study. J Ocul Pharmacol Ther. 2002;18(5):401-409.

37. Glen FC, Crabb DP. Living with glaucoma: a qualitative study of functional implications and patients' coping behaviours. BMC Ophthalmol. 2015; $15: 128$.

38. Skalicky SE, D’Mellow G, House P, Fenwick E; Glaucoma Australia Educational Impact Study Contributors. Glaucoma Australia educational impact study: a randomized short-term clinical trial evaluating the association between glaucoma education and patient knowledge, anxiety and treatment satisfaction. Clin Exp Ophthalmol. Epub 2017 July 9.

39. Owsley C, Rhodes LA, McGwin G Jr, et al. Eye Care Quality and Accessibility Improvement in the Community (EQUALITY) for adults at risk for glaucoma: study rationale and design. Int J Equity Health. 2015; $14: 135$.

40. McDonald L, Glen FC, Taylor DJ, Crabb DP. Self-monitoring symptoms in glaucoma: a feasibility study of a web-based diary tool. J Ophthalmol. 2017;2017:8452840.
Patient Preference and Adherence

\section{Publish your work in this journal}

Patient Preference and Adherence is an international, peer-reviewed, open access journal that focuses on the growing importance of patient preference and adherence throughout the therapeutic continuum. Patient satisfaction, acceptability, quality of life, compliance, persistence and their role in developing new therapeutic modalities and compounds to optimize

\section{Dovepress}

clinical outcomes for existing disease states are major areas of interest for the journal. This journal has been accepted for indexing on PubMed Central. The manuscript management system is completely online and includes a very quick and fair peer-review system, which is all easy to use. Visit http://www. dovepress.com/testimonials.php to read real quotes from published authors. 